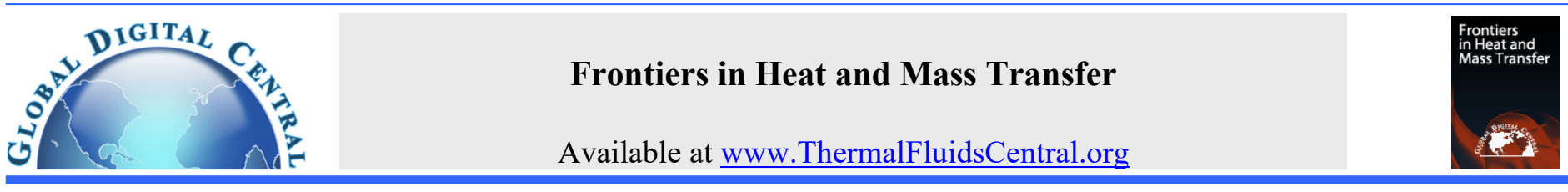

\title{
EXPERIMENTAL INVESTIGATION ON DRAG REDUCTION OF MIXED PEO AND CTAC/NASAL AQUEOUS SOLUTION IN A ROTATING DISK APPARATUS
}

\author{
Wei Tian ${ }^{\mathrm{a}}$, Mingjun Pang ${ }^{\mathrm{a},}, \mathrm{Na} \mathrm{Xu}^{\mathrm{b}, \dagger}$ \\ ${ }^{a}$ School of Mechanical Engineering and Rail Transit, Changzhou University, Changzhou 213164, China \\ ${ }^{b}$ School of Chemical Engineering, Taiyuan University of Technology, Taiyuan 030024, China
}

\begin{abstract}
Drag reduction $(D R)$ by the additive of mixed surfactant and polymer is investigated in detail in a rotating disk apparatus (RDA). Polyethylene oxide (PEO) and Cetyltrimethyl ammonium chloride (CTAC)/sodium salicylate (NaSal) are chosen as polymer and surfactant, respectively. It is investigated on the influence of combination concentration of polymer \& surfactant, temperature and Reynolds number on the drag-reducing rate. The present experimental results show that the drag-reducing rate of the mixed solution is definitely higher than that of the pure PEO or CTAC/NaSal solutions. This phenomenon is especially sharp at the high temperature and/or the large Reynolds number. When the temperature is higher than $30^{\circ} \mathrm{C}$, the net enhancement of $D R$ is the sharpest for the mixed solutions of any CTAC/NaSal concentration and 30 ppm PEO. However, for the mixed solutions of the fixed PEO concentration, the combination concentration of PEO \& CTAC/NaSal, which causes the sharpest enhancement of the $D R$, depends on temperature. In short, comparing with the only addition of PEO or CTAC/NaSal, the coupled addition of PEO \& CTAC/NaSal can obtain the very good drag-reducing effect for the rotating disk apparatus at the high temperature and/or the great Reynolds number.
\end{abstract}

Keywords: rotating disk, drag reduction by additives, synergistic effect, polymer, surfactant

\section{INTRODUCTION}

Rotating machineries used widely in the engineering field consume huge energy, so it is very significant to perform the deep investigation on drag reduction $(D R)$ and energy saving for them. It is well known that the addition of small amounts of additives (such as polymers, surfactants, microbubbles, etc) can cause a significant decrease in frictional drag of turbulent flows in industrial fields (Toms, 1948). Presently, the drag reduction technology by additives has been extensively applied to many industrial processes such as firefighting pipelines, transportation of crude oil in pipelines, central heating and cooling systems, fracturing operation of oil wells, etc. (Hong et al., 2008; Kim et al., 2010; Lian et al., 2020; Nagarajua et al., 2019; Suksamranchit and Sirivat, 2007; Wang et al., 2011; Zhang et al., 2011) A great deal of researches have been carried out on surfactant or polymer drag reduction to understand the dragreducing mechanism and extend effectively its application to industrial fields. The drag reduction $(D R)$ by polymers was well reviewed by the author (Han et al., 2017; Li, 2019; White and Mungal, 2008), and that by surfactants was well reviewed by the author (Wang et al., 2011; Wei et al., 2019).

As the drag-reducing investigations by surfactant and polymer are deeply performed, it is discovered that there are some advantages and disadvantages when polymers or surfactants are alone used as the dragreducing additive. For instance, polymers can induce effectively the drag reduction at a relatively low concentration, and the drag-reducing ranges of Reynolds number and temperature are wide. However, their microstructures of the drag reduction are susceptible to thermal or/and mechanical degradation (Al-Yaari et al., 2013; Andrade et al., 2016; Nsom and Latrache, 2018; Sandoval and Soares, 2016; Soares et al., 2015). And such degradation is permanent and irreversible, which will lead to the permanent lost in the drag-reducing function. As far as surfactants are concerned, the drag-reducing effect can only be achieved when the critical micelle concentration is reached. The Reynolds number range of the effective drag reduction is relatively narrow compared with polymer (Mohamad et al., 2016; Musaab et al., 2016a; Musaab et al., 2016b). There is a critical Reynolds number for each drag-reducing solution with a fixed concentration. If the Reynolds number is larger than the critical value, the drag reduction function will lose due to the collapse of shear induced structures of micelles (Tsukahara et al., 2016; Wei et al., 2012; Xu et al., 2016). Different from molecular structures of polymers, the shear induced structures are regenerative for the dragreducing solution of surfactants when the external conditions (such as the strong shear or the high temperature) are removed (Kim et al., 2011; Matras et al., 2008; Pang et al., 2018). And the drag-reducing rate is relatively high at a low concentration.

The recent investigations show that injecting polymers and surfactants together into the turbulence flow exhibits the better performance of $D R$ than injecting only polymers or surfactants (Liu et al., 2018; Matras and Kopiczak, 2015; Mohsenipor and Pal, 2013a). However, the present studies on compound drag reduction are very limited in rotating machineries. And the mechanism of drag reduction is still not clear too. To understand the excellent $D R$ behavior by the mixed injection of polymers and surfactants, the few studies have been carried out. A detailed review is presented in Table 1.

\footnotetext{
*Corresponding author.Email: pangmj@,cczu.edu.cn

Corresponding author.Email:naxu_xjtu@163.com
} 
Table 1 The review on the DR by the simultaneous injection of polymers and surfactants

\begin{tabular}{|c|c|c|c|}
\hline References & Apparatus & Additives & $M \mathrm{r} / \times 10^{4} \mathrm{~g} / \mathrm{mol}$ \\
\hline $\begin{array}{l}\text { Al-Yaari et al., } \\
2013\end{array}$ & $\begin{array}{l}\text { Pipe } \\
\text { apparatus }\end{array}$ & $\begin{array}{l}\text { PAM, PEO, } \\
\text { \& ARMAC T }\end{array}$ & 470 and 500 \\
\hline $\begin{array}{l}\text { Chai et al., } \\
2019\end{array}$ & $\begin{array}{l}\text { Pipe } \\
\text { apparatus }\end{array}$ & PAM \& SDS & 1600 \\
\hline $\begin{array}{l}\text { Fakhruddin } \\
\text { et al., } 2018\end{array}$ & RDA & PEO \& SDBS & 800 \\
\hline $\begin{array}{l}\text { Kim et al., } \\
2011\end{array}$ & RDA & PAA \& SDS & $\begin{array}{l}45,75 \\
\text { and } 125\end{array}$ \\
\hline $\begin{array}{l}\text { Liu et al., } \\
2018\end{array}$ & $\begin{array}{l}\text { Channel } \\
\text { apparatus }\end{array}$ & $\begin{array}{lr}\text { PAM } & \& \\
\text { CTAC/NaSal }\end{array}$ & 320 \\
\hline $\begin{array}{l}\text { Matras and Kopiczak, } \\
2015\end{array}$ & $\begin{array}{l}\text { Pipe } \\
\text { apparatus }\end{array}$ & $\begin{array}{l}\mathrm{PEO} \& \\
\mathrm{CTAB} / \mathrm{NaSal}\end{array}$ & 800 \\
\hline $\begin{array}{l}\text { Matras and Kopiczak, } \\
2016\end{array}$ & $\begin{array}{l}\text { Pipe } \\
\text { apparatus }\end{array}$ & $\begin{array}{l}\text { PEO \& \& } \\
\text { CTAB/NaSal }\end{array}$ & 800 \\
\hline $\begin{array}{l}\text { Matras et al., } \\
2008\end{array}$ & $\begin{array}{l}\text { Pipe } \\
\text { apparatus }\end{array}$ & $\begin{array}{l}\text { PEO \& \& } \\
\text { CTAB/NaSal }\end{array}$ & 800 \\
\hline $\begin{array}{l}\text { Mohsenipor } \\
\text { and Pal, 2013a }\end{array}$ & $\begin{array}{l}\text { Pipe } \\
\text { apparatus }\end{array}$ & PEO \& OTAC & 700 \\
\hline $\begin{array}{l}\text { Mohsenipor } \\
\text { and Pal, 2013b }\end{array}$ & $\begin{array}{l}\text { Pipe } \\
\text { apparatus }\end{array}$ & $\begin{array}{l}\text { PEO, PAM, } \\
\text { SDS \& OTAC }\end{array}$ & $\begin{array}{l}700 \text { and } \\
1200\end{array}$ \\
\hline $\begin{array}{l}\text { Mohsenipor } \\
\text { and Pal, 2013c }\end{array}$ & $\begin{array}{l}\text { Pipe } \\
\text { apparatus }\end{array}$ & PEO \& SDS & 700 \\
\hline $\begin{array}{l}\text { Mohsenipor } \\
\text { et al., } 2013\end{array}$ & $\begin{array}{l}\text { Pipe } \\
\text { apparatus }\end{array}$ & $\begin{array}{l}\text { PAM } \quad \& \\
\text { OTAC }\end{array}$ & 1200 \\
\hline $\begin{array}{l}\text { Pang et al., } \\
2018\end{array}$ & $\begin{array}{l}\text { Channel } \\
\text { apparatus }\end{array}$ & $\begin{array}{l}\text { PEO \& \& } \\
\text { CTAC/NaSal }\end{array}$ & 700 \\
\hline $\begin{array}{l}\text { Suksamranchit } \\
\text { et al., } 2006\end{array}$ & $\begin{array}{l}\text { Rotational } \\
\text { rheometer }\end{array}$ & PEO \& HTAC & $\begin{array}{l}10,30,60,90 \\
\text { and } 400\end{array}$ \\
\hline $\begin{array}{l}\text { Suksamranchit } \\
\text { and Sirivat, } 2007\end{array}$ & $\begin{array}{l}\text { Rotational } \\
\text { rheometer }\end{array}$ & $\begin{array}{l}\text { PEO, HTAC } \\
\& \mathrm{NaCl}\end{array}$ & 60 and 400 \\
\hline
\end{tabular}

Table 1 (Continue)

\begin{tabular}{|l|l|l|l|}
\hline References & $T /{ }^{\circ} \mathrm{C}$ & $R e$ & $(D R \%)_{\max }$ \\
\hline $\begin{array}{l}\text { Al-Yaari et al., } \\
2013\end{array}$ & $22-60$ & $0-1.8 \times 10^{4}$ & $\sim 35 \%$ \\
\hline $\begin{array}{l}\text { Chai } \text { et al., } \\
2019\end{array}$ & 20 & $\begin{array}{l}2 \times 10^{3} \\
-5 \times 10^{4}\end{array}$ & $\sim 64 \%$ \\
\hline $\begin{array}{l}\text { Fakhruddin } \\
\text { et al., 2018 }\end{array}$ & 25 & $\sim 8.3 \times 10^{5}$ & $\sim 41 \%$ \\
\hline $\begin{array}{l}\text { Kim et al., } \\
2011\end{array}$ & 25 & $\begin{array}{l}4.5 \times 10^{5}- \\
1.25 \times 10^{6}\end{array}$ & $\sim 35 \%$ \\
\hline
\end{tabular}

\begin{tabular}{|l|l|l|l|}
\hline $\begin{array}{l}\text { Liu } \text { et al., } \\
2018\end{array}$ & $25-50$ & $\begin{array}{l}3 \times 10^{3}- \\
6.5 \times 10^{5}\end{array}$ & $\sim 70 \%$ \\
\hline $\begin{array}{l}\text { Matras and Kopiczak, } \\
2015\end{array}$ & 27 & $\begin{array}{l}3 \times 10^{2} \\
-2 \times 10^{5}\end{array}$ & $\sim 75 \%$ \\
\hline $\begin{array}{l}\text { Matras and Kopiczak, } \\
2016\end{array}$ & 27 & $\begin{array}{l}3 \times 10^{2} \\
-2 \times 10^{5}\end{array}$ & $\sim 65 \%$ \\
\hline $\begin{array}{l}\text { Matras } \text { et al., } \\
\text { 2008 }\end{array}$ & 20 & $\begin{array}{l}1 \times 10^{2} \\
-1 \times 10^{5}\end{array}$ & $/$ \\
\hline $\begin{array}{l}\text { Mohsenipor } \\
\text { and Pal, 2013a }\end{array}$ & 25 & $\begin{array}{l}2.5 \times 10^{3} \\
-2.5 \times 10^{5}\end{array}$ & $\sim 80 \%$ \\
\hline $\begin{array}{l}\text { Mohsenipor } \\
\text { and Pal, 2013b }\end{array}$ & 25 & $\begin{array}{l}3.5 \times 10^{3} \\
-3.5 \times 10^{5}\end{array}$ & $\sim 75 \%$ \\
\hline $\begin{array}{l}\text { Mohsenipor } \\
\text { and Pal, 2013c }\end{array}$ & 25 & $\begin{array}{l}2.5 \times 10^{3} \\
-2.5 \times 10^{5}\end{array}$ & $\sim 75 \%$ \\
\hline $\begin{array}{l}\text { Mohsenipor } \\
\text { et al., 2013 }\end{array}$ & 25 & $\begin{array}{l}2.5 \times 10^{3} \\
-2.5 \times 10^{5}\end{array}$ & $\sim 85 \%$ \\
\hline Pang et al., 2018 & 20 & $\begin{array}{l}2 \times 10^{3} \\
-6 \times 10^{4}\end{array}$ & $\sim 70 \%$ \\
\hline $\begin{array}{l}\text { Suksamranchit } \\
\text { et al., 2006 }\end{array}$ & 30 & $\begin{array}{l}2.5 \times 10^{3} \\
5 \times 10^{3}\end{array}$ & and \\
\hline $\begin{array}{l}\text { Suksamranchit } \\
\text { and Sirivat, 2007 }\end{array}$ & 30 & $50 \% 10^{3}$ & $/$ \\
\hline
\end{tabular}

As can be seen from the above review, the present studies on the DR for the mixed solution are relatively few. And the present studies focus mainly on the $D R$ in internal flows (such as pipe and channel flows). The investigations on the influence of temperature on the $D R$ are less. As a matter of fact, rotating machineries, such as pumps and hydroturbines, are extensively used in industrial fields, and their operation temperature rises with the increase of run time. Therefore, it is very necessary to study the drag-reducing phenomena by additives in rotating machineries at different temperature. Besides, there is not still a definitive explanation on the microscopic drag-reducing mechanism of the mixed solution although some mechanism explanations based on experimental results have been presented in literatures (DaRocha et al., 1999; Matras and Kopiczak, 2016; Matras et al., 2008; Suksamranchit et al., 2006).

In view of the above reasons, the $D R$ of the mixed solution for PEO \& $\mathrm{CTAC} / \mathrm{NaSal}$ are investigated in detail in a rotating disk apparatus. Because the aqueous solution of CTAC/NaSal can achieve the excellent drag-reducing effect at a low concentration (25-150 ppm) (Hadri et al., 2011), and NaSal as counter ions can contribute to the formation and stabilization of micelles. PEO is extremely cheap and completely nontoxic. In addition, author (Suksamranchit and Sirivat, 2007) found that the water-soluble polymer such as PEO can interact with the cationic surfactant through the hydrophobic interaction, and the aggregates formed can enhance the drag-reducing effect. Therefore, CTAC and PEO are selected as drag-reducing additives in this paper. Here, it is investigated on the influence of temperature, Reynolds number $(R e)$ and combination concentration of the mixed solution on the drag-reducing rate. Authors performed a preliminary study on the drag-reducing behavior of the mixed solutions of CTAC/NaSal and PEO in a twodimensional rectangular channel at the fixed temperature, and the emphasis is on different $\mathrm{CTAC} / \mathrm{NaSal}$ concentrations at the fixed PEO concentration (Pang et al., 2018). Different from the previous investigation, the present one mentions six temperature. Namely, the drag reduction in the rotating disk apparatus is investigated at $10^{\circ} \mathrm{C}, 20^{\circ} \mathrm{C}$, $30^{\circ} \mathrm{C}, 40^{\circ} \mathrm{C}, 50^{\circ} \mathrm{C}$ and $60^{\circ} \mathrm{C}$, respectively. And, the present investigation is on both different CTAC concentrations at each PEO concentration (30ppm, $50 \mathrm{ppm}, 75 \mathrm{ppm}, 100 \mathrm{ppm}$ and 150ppm) and different PEO concentrations at each CTAC concentration (30ppm, $50 \mathrm{ppm}, 75 \mathrm{ppm}$, $100 \mathrm{ppm}$ and 150ppm). 


\section{EXPERIMENTAL DETAILS}

\subsection{Drag-reducing additives}

A detailed introduction on experimental reagents is presented in Table 2. The drag-reducing reagents are dissolved in deionized water to form the drag-reducing solutions. For simplicity, the concentration of the dragreducing solution refers to the CTAC or/and PEO one in experimental processes. And the weight concentration of $\mathrm{NaSal}$ is the same as CTAC. Namely, their mass ratio is $1: 1$.

Table 2 Experimental additives

\begin{tabular}{|l|l|l|}
\hline Additives & Mr/g/mol & Form and purity \\
\hline Polyethylene oxide (PEO) & $7 \times 10^{6}$ & Powder, 99\% \\
\hline $\begin{array}{l}\text { Cetyltrimethyl ammonium } \\
\text { chloride (CTAC) }\end{array}$ & 320 & Powder, 99\% \\
\hline Sodium salicylate (NaSal) & 160.1 & Powder, 99.5\% \\
\hline
\end{tabular}

\subsection{Design of experimental cases}

It is difficult for PEO to dissolve in water when the concentration is too high (Kong et al., 2016). And when the concentration of the PEO or $\mathrm{CTAC} / \mathrm{NaSal}$ solution is too high, the rheological properties of the solution will has a big change (Chen et al., 2012; Dai et al., 2018). Therefore, the concentrations of both PEO and CTAC/NaSal should not be high. The temperature ranges from $10^{\circ} \mathrm{C}$ to $60^{\circ} \mathrm{C}$, and the temperature interval is $10^{\circ} \mathrm{C}$. The investigations (Kim et al., 2011; Lee et al., 2010) show that the flow will reach the turbulence at the Reynolds number $R e=3 \times 10^{5}$ for the rotating disk apparatus. The maximum Reynolds number depends on the strength and the sealing condition of the present device. Accordingly, the present $R e$ is in the range of $3 \times 10^{5}-5.5 \times 10^{5}$. A detailed design of experimental cases is presented in Table 3 . Note that each concentration of $\mathrm{PEO}$ or $\mathrm{CTAC} / \mathrm{NaSal}$ corresponds to five ones of another reagent in the experimental process, respectively.

Table 3 Experimental cases

\begin{tabular}{|l|l|c|l|}
\hline Reagents & Concentration/ppm & $T /{ }^{\circ} \mathrm{C}$ & $R e$ \\
\hline Reagent 1 & PEO $(30,50,75,100,150)$ & 10,20, & \\
\cline { 1 - 1 } Reagent 2 & CTAC/NaSal $(30,50,75,100,150)$ & 30,40, & $\begin{array}{l}(3-5) \\
\times 10^{5}\end{array}$ \\
\cline { 1 - 2 } $\begin{array}{l}\text { Reagents } \\
\text { land 2 }\end{array}$ & PEO (30,50,75,100,150) \& & 50,60 & \\
\hline
\end{tabular}

Note: All experimental cases in Table 3 are performed. However, limited to space, the results for 50 and $100 \mathrm{ppm}$ and 20 and $50{ }^{\circ} \mathrm{C}$ are not presented here.

\subsection{Experimental apparatus}

The rotating disk device is shown in Fig. 1. It is mainly composed of six parts such as water bath circulation system, motor, rotating disk, control panel, torque sensor and liquid container.

The stainless steel disk with a radius of $50 \mathrm{~mm}$ and a thickness of 3 $\mathrm{mm}$ is finely machined. In experiments, it resides at the center of the liquid container full of test solution. The liquid container is a hollow and shallow cylinder with the jacket, and its diameter and height are $180 \mathrm{~mm}$ and $65 \mathrm{~mm}$, respectively. The jacket is connected to water bath circulation system so to as control the temperature of test solution. The speed range of the motor (WB3000-D) is 30-3000 r/min, and the adjustment accuracy is $\pm 10 \mathrm{r} / \mathrm{min}$. The torque sensor is used to measure the torque of the rotating disk, and its measuring range and accuracy are $0-3.39 \mathrm{~N} \cdot \mathrm{m}$ and $0.0001 \mathrm{~N} \cdot \mathrm{m}$, respectively. The experimental temperature is controlled by the water bath circulation system (DC/HDC0506), and the temperature range is $-5-100^{\circ} \mathrm{C}$. The temperature accuracy of the measurement cell is kept at $\pm 0.01^{\circ} \mathrm{C}$.

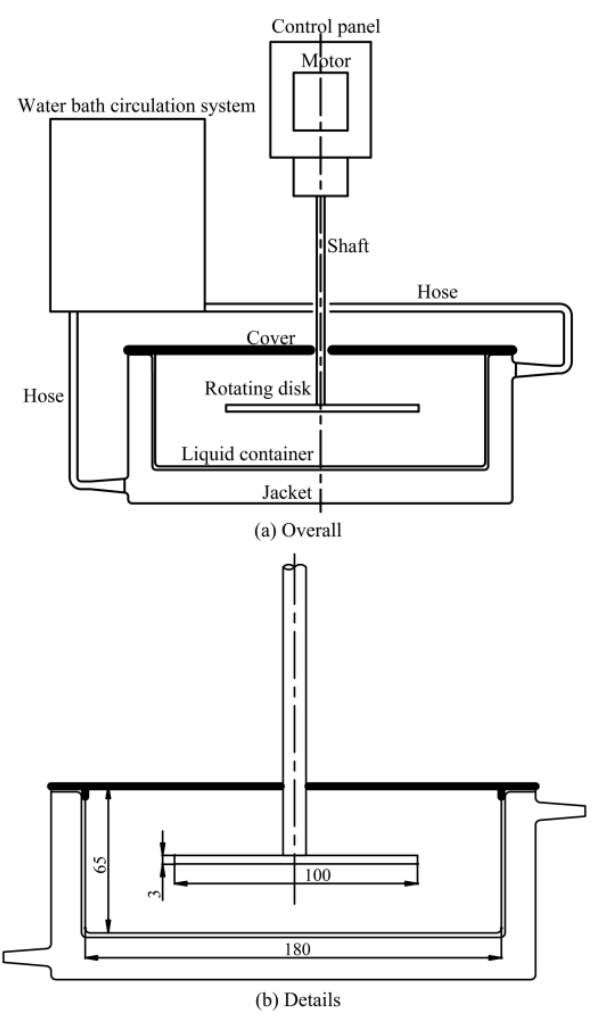

Fig.1 Schematic of the rotating disk device

\subsection{Preparation of experimental solution}

Before the experiment, all reagents are not purified again. First, the mixture of CTAC and NaSal with the equal mass concentration is directly dissolved in the deionized water. The solution is fully stirred with the glass rod until the mixture is completely dissolved. The solution rests in the container for about $24 \mathrm{hr}$ so that it can reach an equilibrium state. Then, a certain amount of PEO powder is evenly spread on the surface of the CTAC/NaSal aqueous solution. Note that when PEO is added into the solution, the agitation should be as slight as possible so as to avoid artificial degradation of the molecular structure of PEO. After PEO is added, the solution rests for $72 \mathrm{hr}$ again to reach a complete equilibrium.

\subsection{Experimental steps}

When the experiment starts, the prepared solution is slowly poured into the liquid container. The water bath circulation system starts working to regulate the temperature of test solution. After the solution temperature reaches the experimental value, the disk starts rotating. The zero setting is first finished before the experimental data is recorded. The speed is adjusted to the experimental one. When the torque value is approximately stable, its value is recorded as the measurement result. Through changing the speed, the whole process of measurement is finished when the speed reach the maximum value. Note that the reagent 1 solution is only applied to the measurement of one Reynolds number. Namely, the fresh solution needs to be prepared for each Reynolds number. The reagent 2 and the mixed solutions can be used to the measurement of several Reynolds numbers. For the same solution, the torque continues to be recorded by changing $R e$ from low to high, and the same measurement is repeated three times. For the fixed $R e$, the average torque for three measurements is applied to calculate the drag-reducing rate. The time interval to record the torque is related to the flow stability one. 


\subsection{Data processing}

The Reynolds number for the flow induced by the rotating disk is calculated by Eq. (1).

$$
\operatorname{Re}=\frac{\rho r^{2} \omega}{\mu}
$$

Where $\rho$ is the liquid density at the test temperature, $\mathrm{kg} \cdot \mathrm{m}^{-3} ; \mu$ is the liquid viscosity at the test temperature, $\mathrm{Pa} \cdot \mathrm{s} ; r$ is the radius of the disk, $\mathrm{m}$; and $\omega$ is the angular velocity, $\mathrm{rad} \cdot \mathrm{s}^{-1}$.

The drag-reducing rate is calculated according to Eq. (2).

$D R \%=\frac{\Pi_{\mathrm{s}}-\Pi_{\mathrm{p}}}{\Pi_{\mathrm{s}}} \times 100 \%$

Here, $\Pi_{\mathrm{s}}$ and $\Pi_{\mathrm{p}}$ are the measured torques of the pure water and the dragreducing solution at the same temperature and the same Reynolds number. $D R \%$ denotes the drag-reducing rate.

Note that, for the calculation of the Reynolds number, the density and viscosity of water are only used for convenient comparison and analysis according to the references (Lee et al., 2010; Wu et al., 2008).

\section{RESULTS AND DISCUSSION}

To understand the drag-reducing performance of the mixed solutions, the influence of $\mathrm{PEO}$ or $\mathrm{CTAC} / \mathrm{NaSal}$ concentration on the drag-reducing rate is investigated at different temperature, respectively. The influence of temperature on the maximum drag-reducing rate is also investigated at different $R e$.

\subsection{Accuracy check of experimental apparatus}

To check the reliability of the present experimental apparatus, the viscous torques of pure water against $R e$ are measured three times at $20^{\circ} \mathrm{C}$, as shown in Fig. 2. For comparison, empirical values by Eq. (3) (Wu et al., 2008) are also plotted in Fig. 2.

$\Pi_{s}=\frac{0.023}{2} r\left(\frac{d}{r}\right)^{0.1} \frac{\mu^{2}}{\rho} R e^{1.94}$

Where $d$ denotes the axial distance between the upper surface of the disk and the inner wall of the vessel, $\mathrm{m}$.

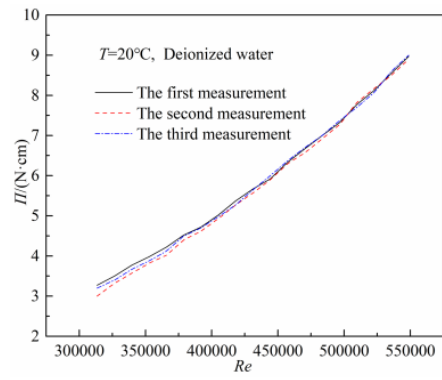

(a) Repeatability check

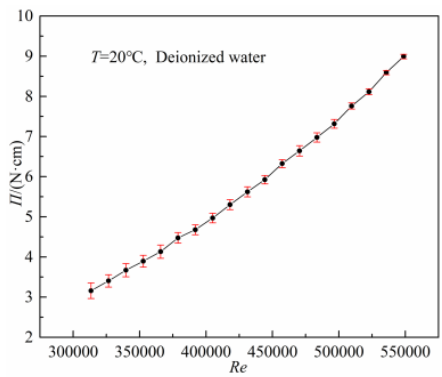

(b) Accuracy check
Fig. 2 Accuracy check of experimental results

One can see from Fig. 2 that the repeatability of experimental results is good, and it becomes better and better as the Reynolds number increases. Additionally, the maximum deviation between the experimental and empirical values is $\sim 8.5 \%$, and the deviation gradually decreases too as $R e$ increases. These show fully the reliability of the present experimental apparatus.

\subsection{Influence on concentration of $\mathrm{CTAC} / \mathrm{NaSal}$ when the PEO concentration is fixed}

Firstly, it is investigated on the influence of the reagent 2 concentration on the drag-reducing rate $(D R \%)$ of the mixed solution for the fixed concentration of reagent 1 as $R e$ increases at different temperature, as showed in Fig. 3. For comparison, the $D R \%$ of the solution of reagent 1 is plotted in Fig. 3. Note that there are many reports on the drag reduction of the solution of reagent 1 (Dai et al., 2021; Lawrence and Panagiota, 2019; Zhang et al., 2018). Therefore, the present focus discusses the influence of the addition of reagent 2 on the drag-reducing performance of the solution of reagent 1 . And the analyses on the drag-reducing behavior for the solution of reagent 1 are not repeated again.

It can be seen from Fig. 3 that $D R \%$ of the mixed solution depends on the magnitudes of $R e$, temperature and concentration of the dragreducing solution. When the measured temperature is the same, the curves of the $D R \%$ against $R e$ are similar for the mixed solutions with the same reagent 1 and different reagent 2 concentrations. The $D R \%$ increases basically as the concentration of reagent 2 does when other parameters are the same. When the temperature and concentration of the measured solutions are definite, the $D R \%$ increases with increasing $R e$ in the present range. When the concentration and $R e$ are definite, the $D R \%$ of the solutions increases first and then decreases with the increase of temperature.
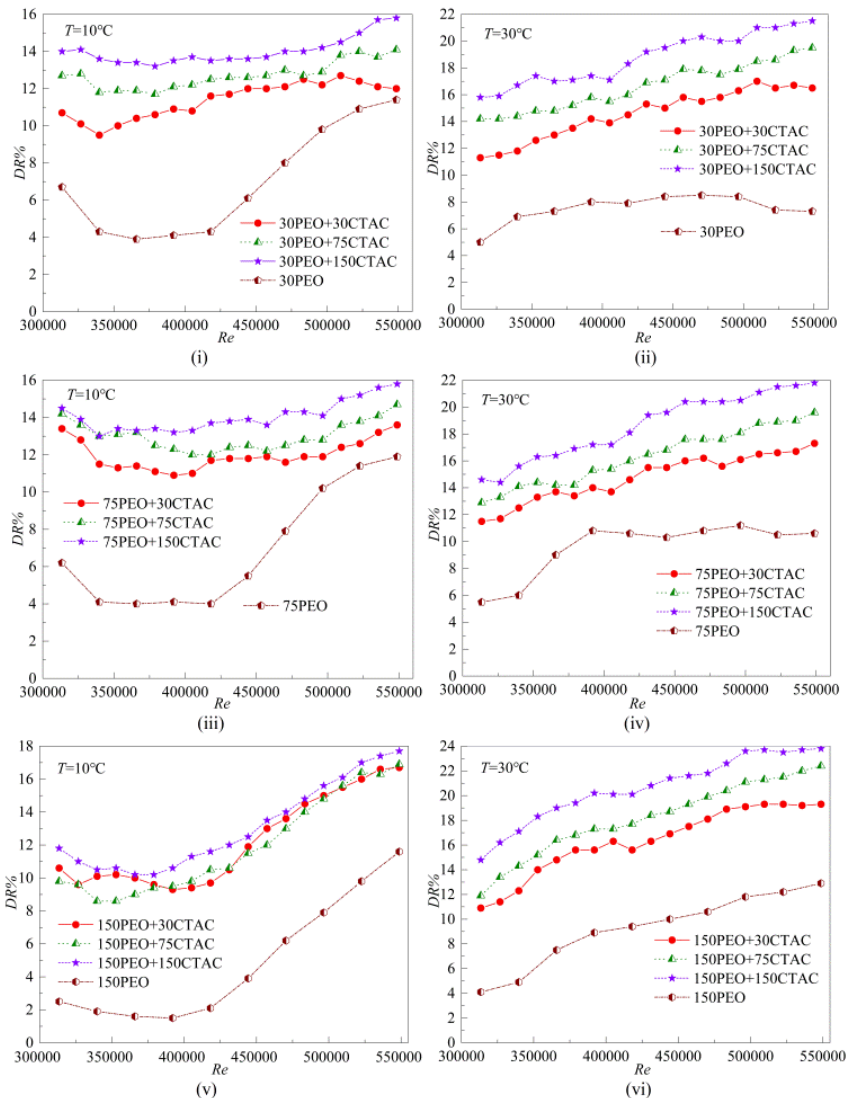

(a) $T=10$ and $30^{\circ} \mathrm{C}$

Fig. 3 The influence of the CTAC/NaSal concentration on the dragreducing rate $(D R \%)$ of the $\mathrm{PEO}$ solution 


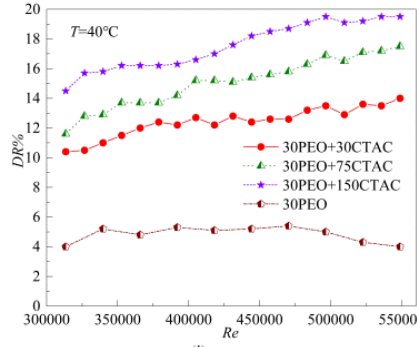

(i)
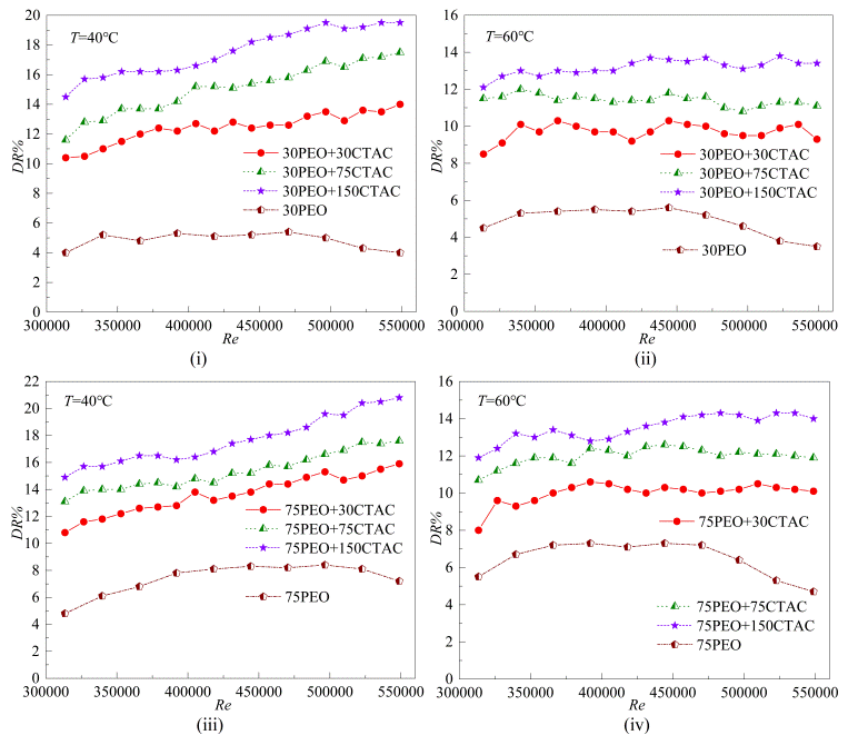

(ii)

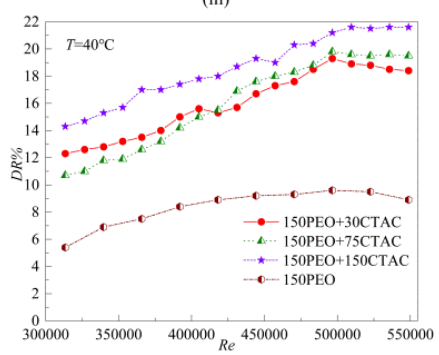

(v)

(b) $T=40$ and $60^{\circ} \mathrm{C}$



(iv)

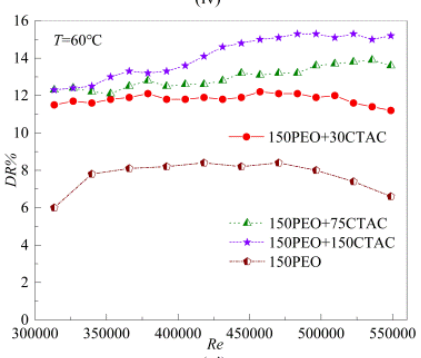

(vi)

Fig. 3 (Continue)

Additionally, comparing with the $D R$ by the only reagent 1 , the $D R$ by the mixed reagents shows the following characteristics. (i) The $D R \%$ of all mixed solutions are larger than those of the corresponding solution of reagent 1 . That shows that the drag-reducing ability of the solution of reagent 1 is enhanced due to the addition of a certain amount of regent 2. This may be due to the fact that much more and larger aggregates inducing $D R$ form in the mixed solution, and thus the drag-reducing effect is better. (ii) The mixed solutions have the relatively high dragreducing rate at the high temperature or/and the large $R e$. For the present solution of reagent 1 , the $D R \%$ is the highest at $\sim 20^{\circ} \mathrm{C}$. However, the mixed solutions obtain the highest drag-reducing rate at $\sim 30^{\circ} \mathrm{C}$. Those phenomena mean that the $R e$ and temperature ranges of the $D R$ are wider for the mixed solutions than those of reagent 1 . Namely, the dragreducing microstructures formed by reagents 1 and 2 should have the good resistance ability to the high temperature and the strong shear. The micelle structures of CTAC/NaSal may attach the long chain or form cross junction in the PEO molecules. On the one hand, the micelle structures of $\mathrm{CTAC} / \mathrm{NaSal}$ may increase the shear strength of the long chain of PEO and play a protective role. On the other hand, they enhance the stability of connection, namely, the aggregate structure becomes stronger. (iii) The influence of $R e$ and temperature on the drag-reducing performance is basically similar for the solutions of reagent 1 and mixed reagent. That denotes that the addition of reagent 2 into the solution of reagent 1 only increases the $D R \%$ but does not change the drag-reducing trend. This means that the main backbone structure of the aggregate is still the long chain of PEO, and the micelle structure of CTAC/NaSal attached to the long chain of PEO only increases the volume and stability of the aggregate.

To understand well the drag-reducing enhancement of the solution of reagent 1 due to the addition of reagent 2, Fig. 4 shows that the difference of the drag-reducing rate $(D D R \%)$ between the reagent 1 and mixed solutions changes with changing temperature, Re and the concentration of reagents 1 and 2 .


(b) $T=40$ and $60^{\circ} \mathrm{C}$

Fig. 4 The enhancement of drag reduction by the addition of $\mathrm{CTAC} / \mathrm{NaSal}$ on the PEO solution 
As showed in Fig. 4, the drag-reducing enhancement depends tightly on the above three parameters. For the drag-reducing solutions with the same concentration of reagent 1 , the influence of concentration of reagent 2 on $D D R \%$ is similar.

For the present cases, the drag-reducing enhancement (DDR\%) increases with increasing the concentration of reagent 2. The high concentration can increases of the number of micelles of CTAC/NaSal, which further increases the volume and stability of the aggregate. However, the following phenomena are worth noting. (i) For the cases with the low temperature and the high concentration of reagent 1 (such as $150 \mathrm{ppm}$ at $10^{\circ} \mathrm{C}$ ), the addition of reagent 2 has almost no influence on the drag-reducing enhancement of the solution of reagent 1 . The apparent viscosity of the PEO solution with a high concentration is very large at the low temperature, and thus the flow frictional resistance is large too. So the enhancement effect may be greatly weakened. (ii) For the solution of reagent 1 with the high drag-reducing rate (such as 30 ppm at $20^{\circ} \mathrm{C}$ ), the drag-reducing enhancement is relatively weak. Generally, the drag-reducing enhancement is very sharp when the $D R \%$ for the solution of reagent 1 is very small.

It can be also seen from Fig. 4 that the relationship between the dragreducing enhancement and the parameters such as temperature, $R e$ and the concentration of reagent 1 is very complicated. The influence of those parameters on the drag-reducing enhancement is interrelated. The dragreducing enhancement against $R e$ is different with the increase of temperature. When the temperature is low (such as $10^{\circ} \mathrm{C}$ ), the dragreducing enhancement increases first and then decreases as the Re increases. When the temperature is high (such as $40{ }^{\circ} \mathrm{C}$ ), the dragreducing enhancement increases approximately as the $R e$ increases. It seems that the drag-reducing enhancement is relatively sharp for the following two conditions. One is the high concentration of reagent 1 and the low temperature. The other is the low concentration of reagent 1 and the high temperature

\subsection{Influence on concentration of PEO when the CTAC/NaSal concentration is fixed}

Secondly, it is investigated on the influence of the concentration of reagent 1 on the $D R \%$ of the mixed solution with the fixed concentration of reagent 2 . The $D R$ by reagent 2 is not the present focus either. The $D R$ by surfactants can refer to the literatures (Cai et al., 2012; Fu et al., 2015; Li et al., 2004; Li et al., 2005; Wei et al., 2006; Yu and Kawaguchi, 2006). The effect of the injection of reagent 1 on the $D R$ of the reagent 2 solution will be discussed in detail below. Fig. 5 shows the influence of temperature, $R e$ and concentration on the $D R \%$ of the mixed solutions. For comparison, the $D R \%$ of the solution of reagent 2 is also plotted in Fig. 5.

As showed in Fig. 5, the drag-reducing behavior of the mixed solutions is distinctly different from that of the reagent 2 solution. The mixed solutions shows the excellent performance of the $D R$ at the high temperature or/and the large $R e$. That shows that the addition of reagent 1 widens the effective ranges of $R e$ and temperature for the $D R$ by reagent 2. The temperature has the sharp influence on the trend of the $D R \%$ against $R e$. When the temperature is higher than $20^{\circ} \mathrm{C}$, the change trend of the $D R \%$ against $R e$ is similar. However, when the temperature is lower than $20^{\circ} \mathrm{C}$, the concentration of reagent 1 has the sharp influence on the curve of the $D R \%$. The $D R \%$ curve against $R e$ are similar when the concentration of reagent 1 is equal to 100 and $150 \mathrm{ppm}$, but they are similar when the reagent 1 concentration is equal to 30,50 and $75 \mathrm{ppm}$. As a matter of fact, the apparent viscosity of the drag-reducing solution is related to the concentration of additives. And the flow frictional resistance of the solution depends tightly on the apparent viscosity of the drag-reducing solution. Therefore, the $D R \%$ curves of the mixed solutions change as the concentration changes.

It can also be seen from Fig. 5 that, for the overwhelming majority of cases, the addition of a certain amount of reagent 1 increases the $D R \%$ of the reagent 2 solution. Especially, when the $R e$ or/and temperature are high, the $D R \%$ of the mixed solutions are sharply higher than those of the solution of reagent 2 under the same condition.
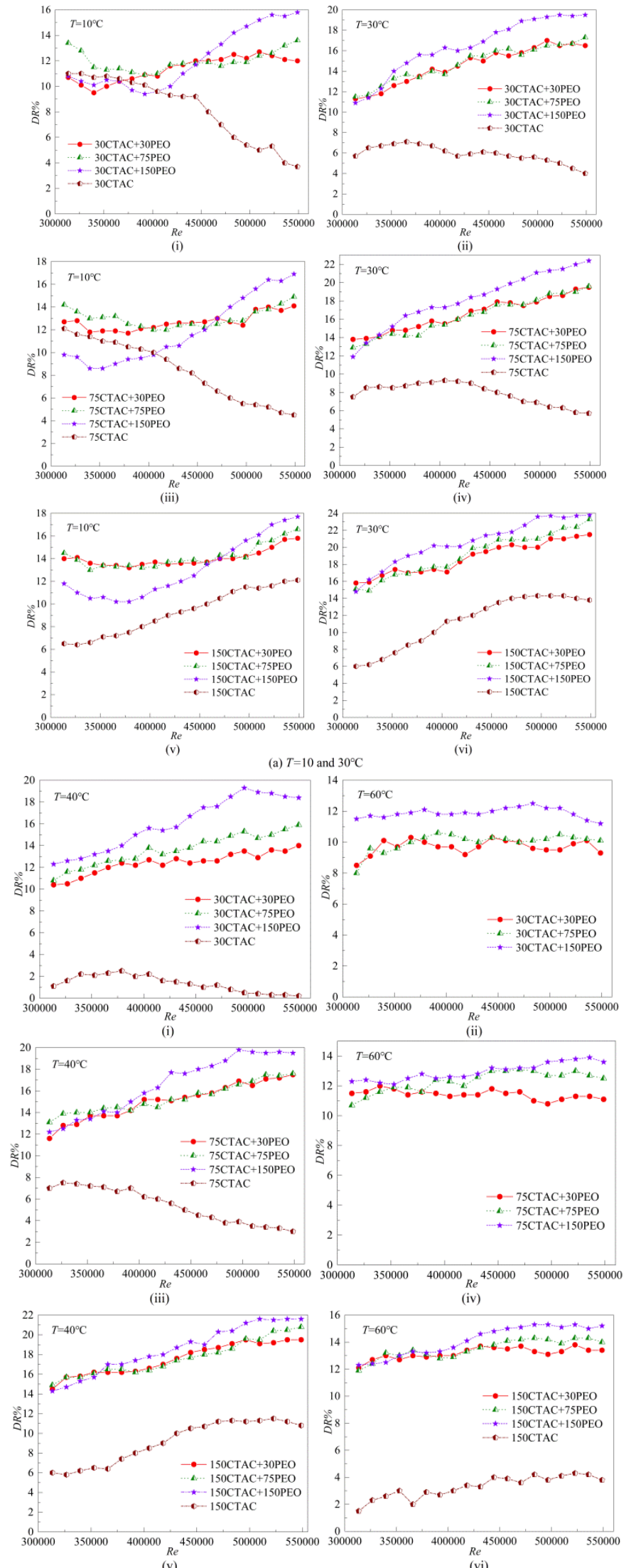

(b) $T=40$ and $60^{\circ} \mathrm{C}$

(vi)

Fig.5 The influence of the PEO concentration on the drag-reducing rate $(D R \%)$ of the $\mathrm{CTAC} / \mathrm{NaSal}$ solution 
This further shows that the drag-reducing effect will become better when the new microstructures (aggregates) of $D R$ form in the mixed solution. Under these conditions, the drag-reducing phenomena disappear for the solution of reagent 2 (such as the solution of reagent 2 concentrations of $30 \mathrm{ppm}$ at the temperature larger than $30^{\circ} \mathrm{C}, 75 \mathrm{ppm}$ at the temperature larger than $40^{\circ} \mathrm{C}$, and $150 \mathrm{ppm}$ at $60^{\circ} \mathrm{C}$ ).

To understand well the drag-reducing enhancement of the solution of reagent 2 due to the addition of reagent 1, Fig. 6 shows that the difference of the drag-reducing rate $(D D R \%)$ between the reagent 2 and mixed solutions depends on temperature, $R e$ and concentration of reagent 1 and reagent 2. One can see from Fig. 6 that the drag-reducing enhancement $(D D R \%)$ increases rapidly as the $R e$ increases when the temperature and concentration of the reagent 2 solution are low. When the reagent 2 concentration is lower than and equal to $75 \mathrm{ppm}$, the increase of the drag-reducing enhancement against $R e$ gradually become slight with the increase of temperature in the present range of Re. When the reagent 2 concentration is higher than $75 \mathrm{ppm}$, the reagent 1 concentration has the large influence on the change trend of the dragreducing enhancement against $R e$ at the low temperature (such as $10^{\circ} \mathrm{C}$ ). The influence of the reagent 1 concentration on it becomes gradually weak with the increase of temperature.

Note that the drag reduction of the solution of reagent 2 is weaken (namely, the $D R \%$ decreases) at the low temperature and the low $R e$ (such as $R e=4.0 \times 10^{5}$ and $T=10^{\circ} \mathrm{C}$ ) due to the addition of reagent 1 . And the higher the concentration of reagent 1 is, the sharper the decrease of the drag reduction is. It seems that the drag-reducing enhancement of the reagent 2 solution due to the addition of reagent 1 is the sharpest under the conditions of the large $R e$ at the temperature of $40^{\circ} \mathrm{C}$ when the concentration of reagent 2 is less than $150 \mathrm{ppm}$. For the reagent 2 solution of $150 \mathrm{ppm}$, the drag-reducing enhancement is the sharpest at the temperature of $60^{\circ} \mathrm{C}$, and the $R e$ has the slight influence on it.
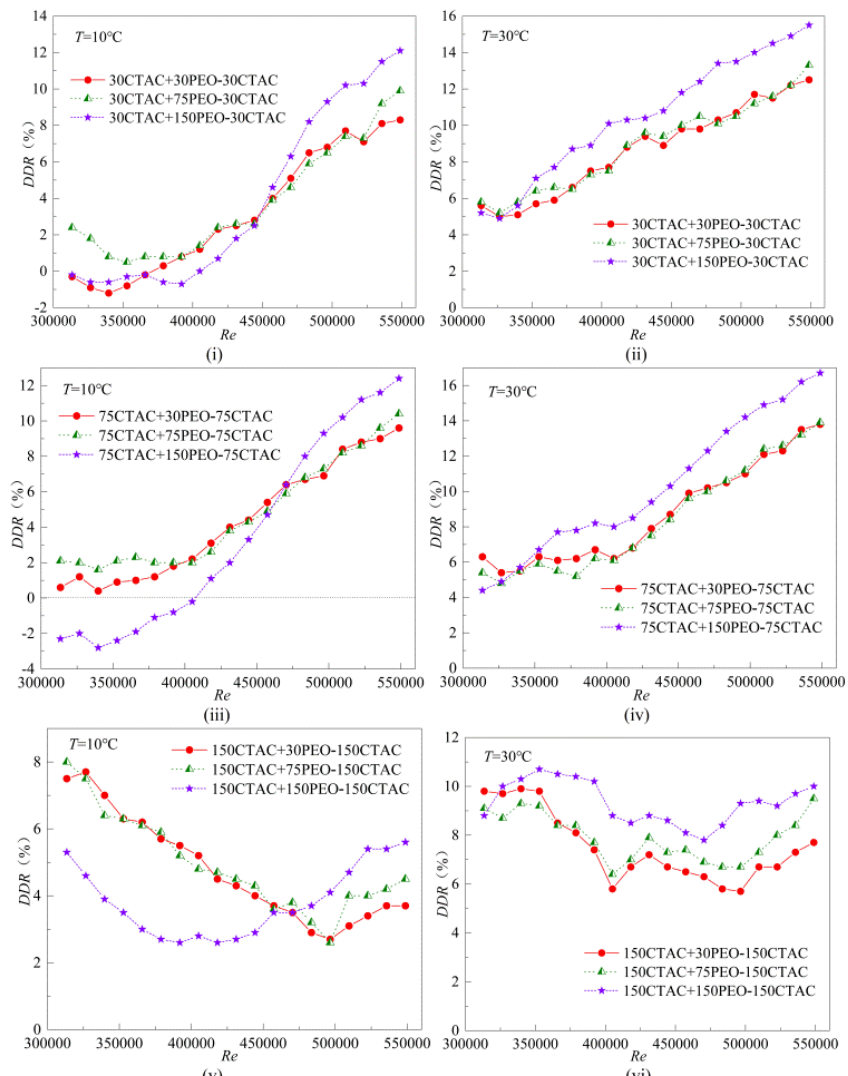

(a) $T=10$ and $30^{\circ} \mathrm{C}$

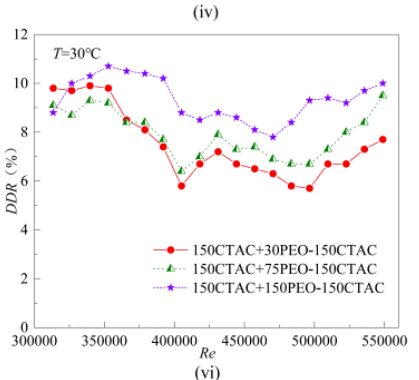

(vi)

Fig. 6 The enhancement of drag reduction by the addition of PEO on the CTAC/NaSal solution
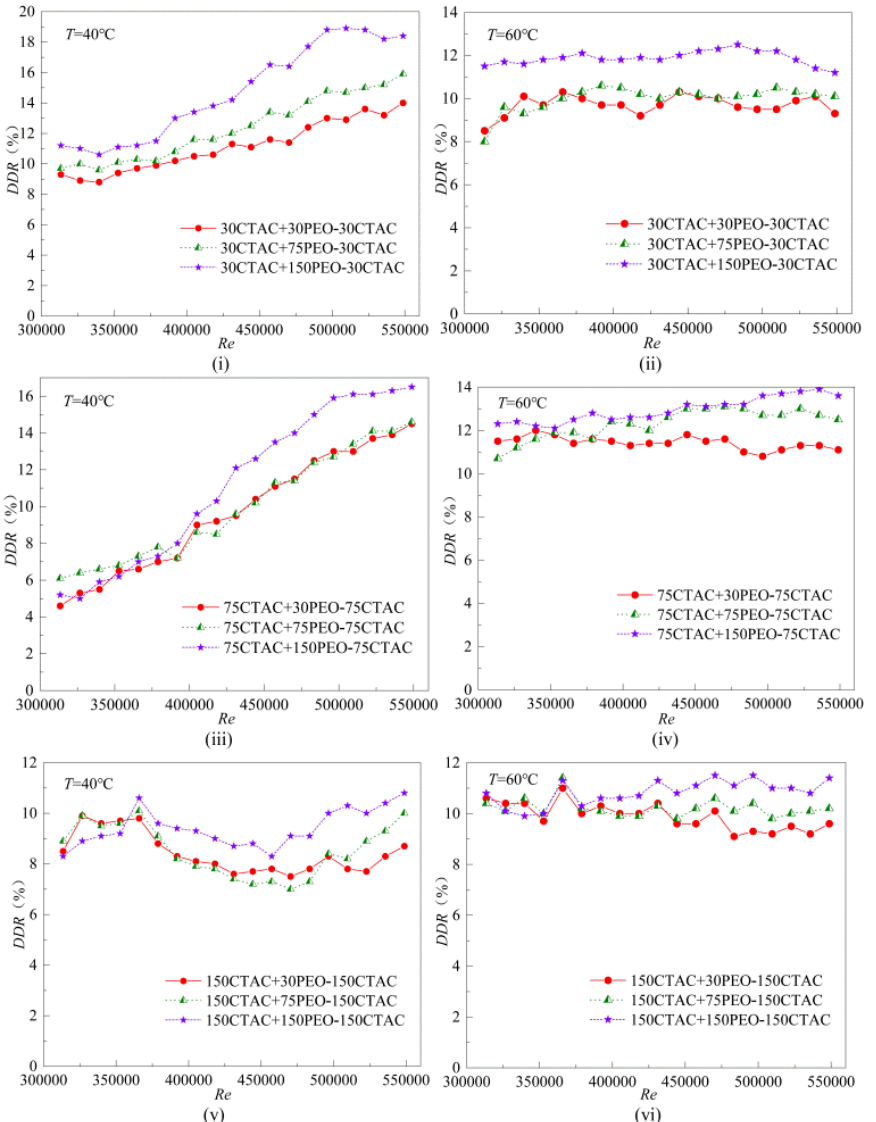

(b) $T=40$ and $60^{\circ} \mathrm{C}$

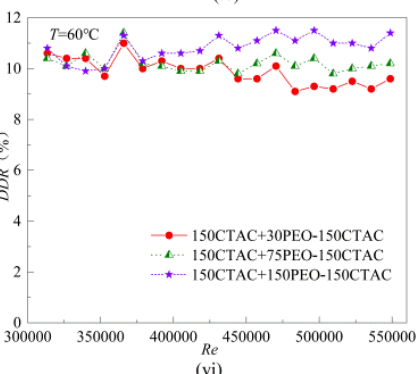

Fig. 6 (Continue)

So far, many investigations have showed that the drag reduction by reagent 1 has the following features. There are two main advantages. (i) A very small amount of reagent 1 can cause the effective drag reduction. (ii) The ranges of $R e$ and temperature for the effective drag reduction are very wide. The obvious disadvantage is the bad durability of the drag reduction because the PEO chain breaks easily down under the strong shear and cannot repair themselves after fracture. For the drag reduction by reagent 2, the advantages show the following two aspects. (i) A small amount of CTAC/NaSal can lead to a very high drag-reducing rate at the limited ranges of $R e$ and temperature. (ii) The microstructures inducing the drag reduction can repair themselves after fracture when the external adverse conditions (such as the strong shear and the high temperature) are removed. The obvious disadvantage is that the ranges of $R e$ and temperature for the effective drag reduction are very narrow. And the maximum of $R e$ and temperature is very low. The present investigations show fully that the $D R$ of the mixed solutions combines the advantages of the $D R$ by them of reagent 1 and reagent 2. Namely, the $D R \%$ is high, and the ranges of $R e$ and temperature are wide for the effective drag reduction.

\subsection{Analyses on the net enhancement of the drag-reducing rate}

As the above analyses show, the $D R \%$ of the mixed solution is basically higher than that of the corresponding solution of reagent 1 or reagent 2 . However, that does not mean that the $D R$ is definitely enhanced. From an economical point of view, only when the $D R \%$ of the mixed solution is higher than the sum of the $D R \%$ of the corresponding solutions of reagent 1 and reagent 2 , this means that the $D R$ is really enhanced. 

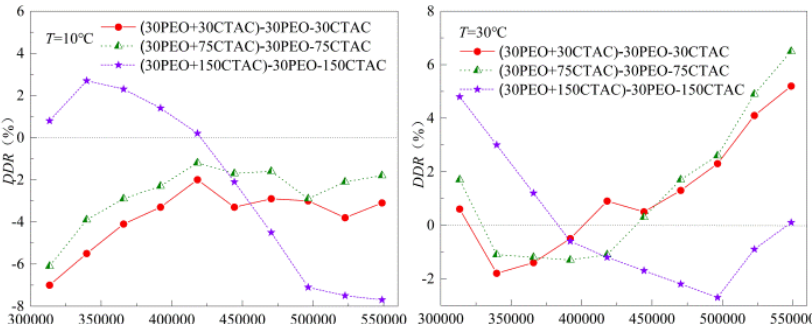

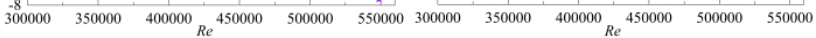
(i)
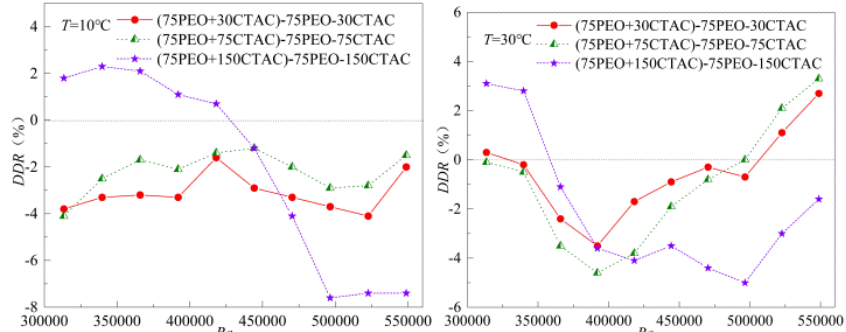

(iii)
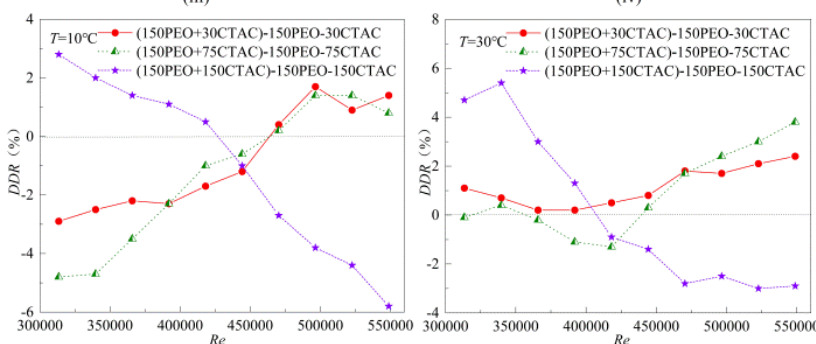

(vi)

(v) $\quad$ (a) $T=10$ and $30^{\circ} \mathrm{C}$

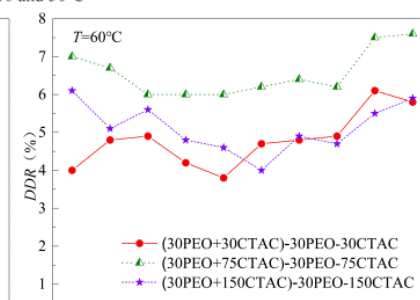

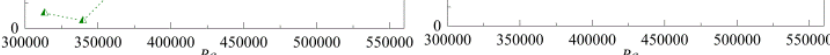

(i)
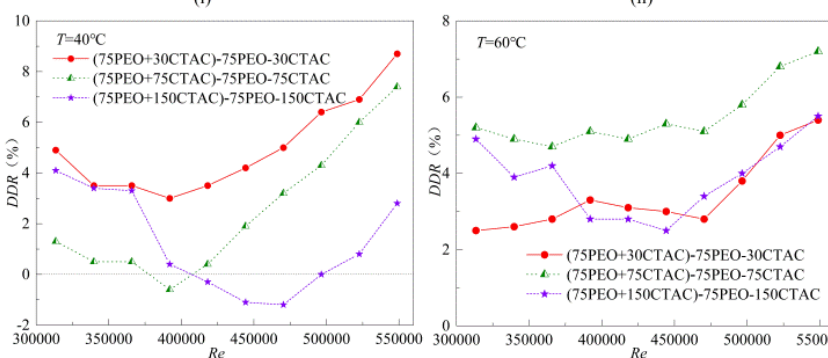

(iii)

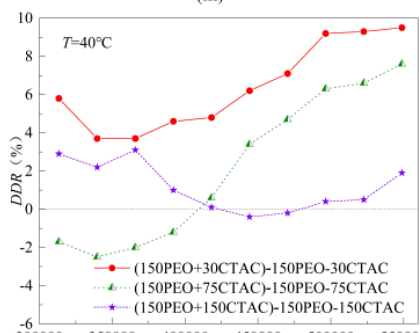

(iv)

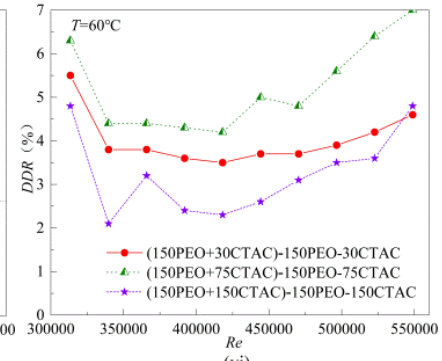

(v)

(b) $T=40$ and $60^{\circ} \mathrm{C}$
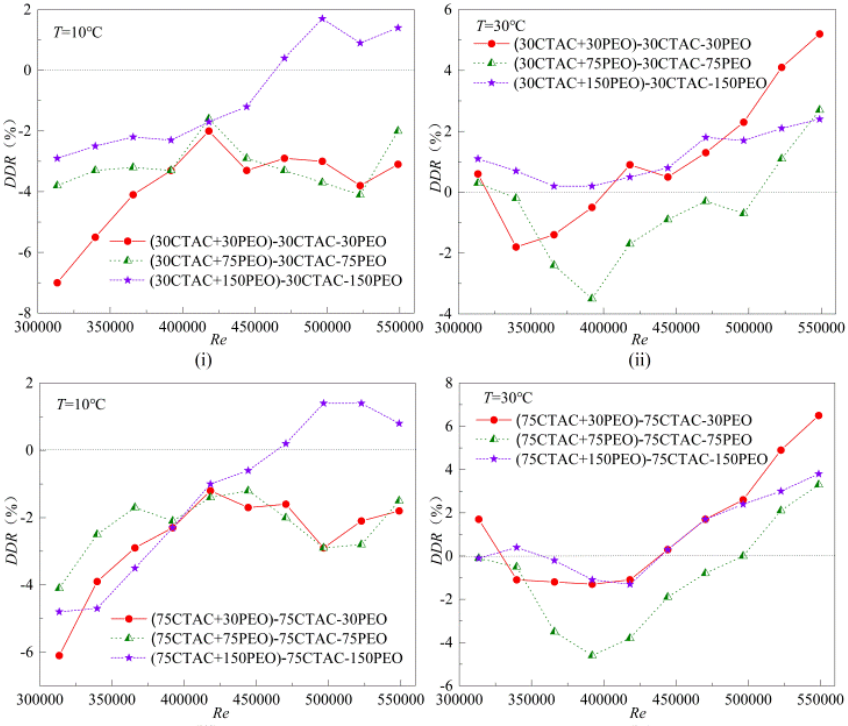
(iii)
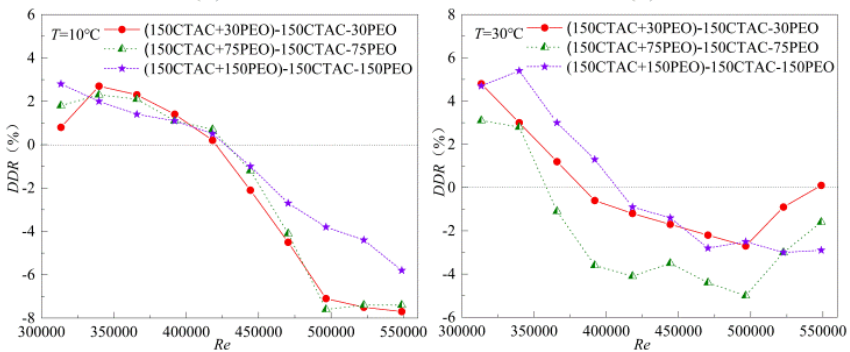

(v) (a) $T=10$ and $30^{\circ} \mathrm{C}$
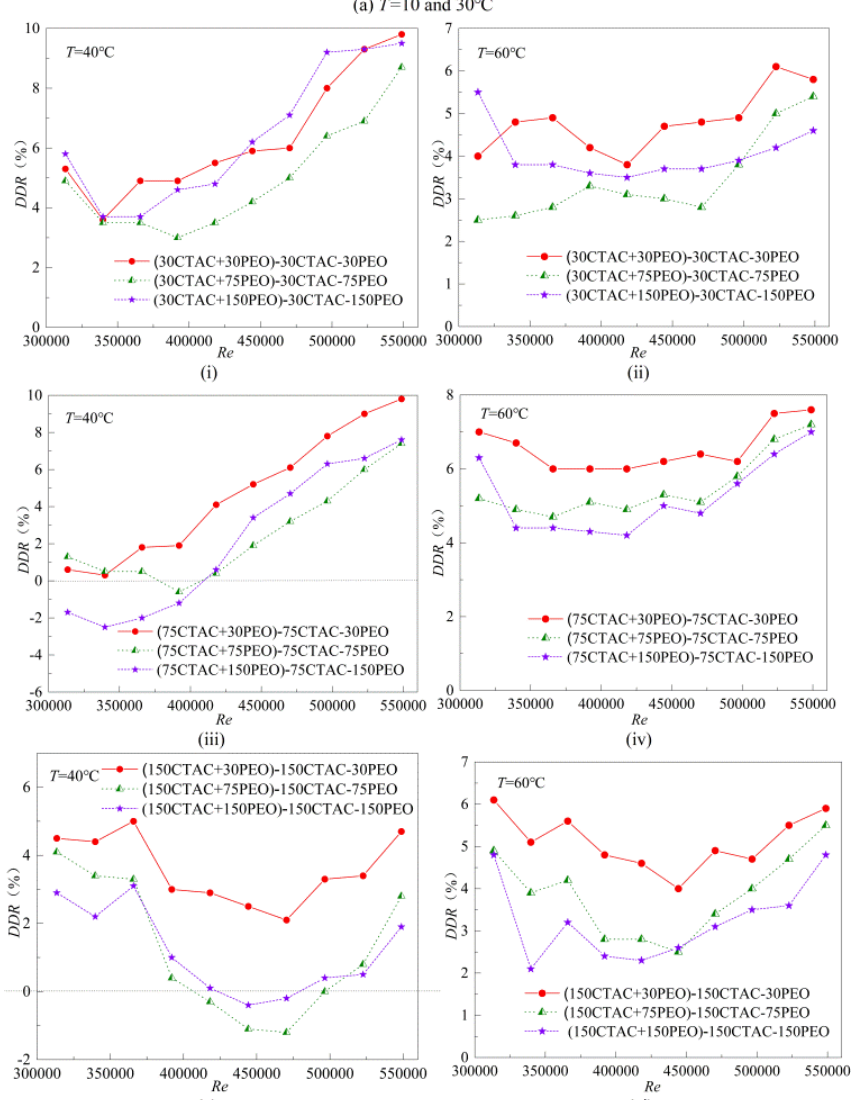

(b) $T=40$ and $60^{\circ} \mathrm{C}$
Fig. 7 The net enhancement of drag reduction of the mixed solution for the fixed PEO concentration
Fig. 8 The net enhancement of drag reduction of the mixed solution for the fixed CTAC/NaSal concentration 
Figures 7 and 8 show the net difference of the drag-reducing rate (i.e., the difference between the $D R \%$ of the mixed solution and the $D R \%$ sum of the corresponding solutions of reagent 1 and reagent 2) against $R e$ at different temperature. Fig. 7 shows the net difference of the dragreducing rate (the net $D D R \%$ ) between the mixed solutions of the fixed reagent $1 \&$ different reagent 2 concentrations and the corresponding solutions. One can see from Fig. 7 that the change of the net $D D R \%$ against $R e$ is related mainly to the temperature. The overwhelming majority of the net $D D R \%$ are less than zero when the temperature is lower than $30^{\circ} \mathrm{C}$. When the temperature is equal $30^{\circ} \mathrm{C}$, the net $D D R \%$ is larger than zero under the certain conditions. They are related to the concentration combination and $R e$. The relationship between them is complicated. When the temperature is higher than $30^{\circ} \mathrm{C}$ and less than $60^{\circ} \mathrm{C}$, the net $D D R \%$ is larger than zero for the overwhelming majority of cases except that both reagent 1 and reagent 2 concentrations are very high at the same time. When the temperature is equal to $60^{\circ} \mathrm{C}$, the net $D D R \%$ is larger than zero for all cases. Namely, the $D R$ is totally enhanced.

Figure 8 shows the net $D D R \%$ between the mixed solutions of the fixed reagent $2 \&$ different reagent 1 concentrations and the corresponding solutions. One can see from Fig. 8 that the change of the net $D D R \%$ against $R e$ is related to the reagent 2 concentration and the temperature. When the reagent 2 concentration is less than $100 \mathrm{ppm}$, the net $D D R \%$ increases with the increase of $R e$. The increasing extent of them become slight with the increase of temperature. When the reagent 2 concentration is larger than $100 \mathrm{ppm}$, the net $D D R \%$ decreases with the increase of the $R e$ at the temperature less than $40^{\circ} \mathrm{C}$. And it decreases first and then increases with the increase of the $R e$ at the temperature larger than and equal to $40^{\circ} \mathrm{C}$.

At the low temperature $\left(\leq 20^{\circ} \mathrm{C}\right)$, the net $D D R \%$ is less than or approximately close to zero. That is to say that the drag reduction is almost not enhanced. However, with the increase of temperature, the net $D D R \%$ tends to be larger than zero. Especially, at the high temperature $\left(60^{\circ} \mathrm{C}\right)$, the net $D D R \%$ is larger than zero for all cases (namely, the $D R$ is entirely enhanced). For the fixed concentration of reagent 2 , the smaller the reagent 1 concentration is, the larger the net $D D R \%$ is (i.e., the sharper the $D R$ enhancement is). Similarly, when both reagent 1 and reagent 2 concentrations are high at the same time, the net $D D R \%$ is less than zero at the temperature of $40^{\circ} \mathrm{C}$ and $50^{\circ} \mathrm{C}$.

In short, when the temperature is higher than $30^{\circ} \mathrm{C}$, the following phenomena can be summarized from Figs. 7 and 8 . For the fixed concentration of reagent 1 (or reagent 2), the net $D D R \%$ increases as the $R e$ increases. In fact, with the increase of $R e$, the long chain of PEO can be extended much fully. This will leads to that the micelle structures of CTAC/NaSal can be much closely combined with the long chain of PEO. Thus, the aggregate size is larger and its strength is high. So the dragreducing effect will be better. And, for the fixed $R e$, it basically decreases as the concentration of reagent 2 (or reagent 1) increases. It can be concluded that the drag-reducing enhancement is very sharp when the temperature is at least higher than $30^{\circ} \mathrm{C}$; for the mixed solutions of the fixed concentration of reagent 2, the drag-reducing enhancement is the sharpest when the concentration of reagent 1 is $30 \mathrm{ppm}$; and for the mixed solutions of the fixed concentration of reagent 1 , the concentration combination of reagents 1 and 2, which causes the sharpest enhancement of the $D R$, depends on the temperature. That can be explained by the following reasons. On the one hand, the apparent viscosity of PEO solution decreases sharply at the high temperature, which reduces the negative effect of $D R$ induced by the viscosity. On the other hand, the drag-reducing solution of CTAC/NaSal has the poor resistance to high temperature, and the $D R \%$ of it decreases rapidly at the high temperature, and even disappears. However, the mixed solution of CTAC/NaSal and PEO is very resistant to high temperature, so the drag reduction rate increases significantly.

\section{ANALYSES OF DRAG REDUCING MECHANISM}

The drag-reducing mechanism by reagent 1 or reagent 2 will not be analyzed. The interested reader can refer to the references ( $\mathrm{Gu}$ et al., 2020; Wang et al., 2011; White and Mungal, 2008). On the basis of the drag-reducing mechanism by reagent 1 or reagent 2 , the combined dragreducing mechanism by reagents 1 and 2 is analyzed in detail below.

It is well known that when the concentration of surfactant reaches the critical micelle concentration (CMC) (Matras et al., 2008; Mohsenipor et al., 2013), spherical and rod-like microscopic micelle structures can be formed in the surfactant solution. These structures can inhibit the turbulence and reduce the friction force, and thus the effect of drag reduction appears. When the curly long molecular chain of polymer in the turbulent flow is stretched, the similar drag-reducing effect to surfactant micelles appears. In the mixed solution of surfactant and polymer, it is assumed that the following two phenomena happen. On the one hand, the stretching of long molecular chains is promoted due to the hydrophobic and electrostatic interactions between polymer molecular chains and surfactant molecules. On the other hand, surfactant molecules can aggregate into micelles along elongated long molecular chains. A very small amount of surfactant can lead to the micelle formation, and the corresponding concentration is called the critical aggregation concentration (CAC) (Hou et al., 1999; Matras and Kopiczak, 2015). The new macromolecular structure is called the aggregate. Some researchers (Kim et al., 2011; Matras and Kopiczak, 2015; Matras et al., 2008; Mohsenipour et al., 2013) proposed several aggregate models and introduced the corresponding mechanism explanation.

Matras and Kopiczak (2015), and Matras et al. (2008) proposed the model of sphere structure and chain structure. The sphere structure is formed by the long molecular chain of polymer around the surfactant micelle, and the long molecular chain of polymer is cross-linked around the surfactant micelle. The chain structure is formed by incomplete wrapping of the long polymer chain around the rod-like micelles, which are connected to the concave side of the polymer chain to form aggregates. These aggregates under the shear take an orientation in agreement with the principle of minimum resistance. With the increase of the Reynolds number (i.e., the shear action becomes stronger), the aggregates will be stretched and extended, thus inducing the drag reduction. Mohsenipour et al. (2013) proposed the model of necklace structure. This model is that the rod-like micelles of the surfactant are completely attached to the main chain of the polymer, forming a threedimensional interconnected network necklace structure. The increase of the surfactant concentration can lead to the increase in the length of the rod-like micelles, which is beneficial to the formation of the micro necklace drag reduction structure. Thus, the drag reduction is promoted.
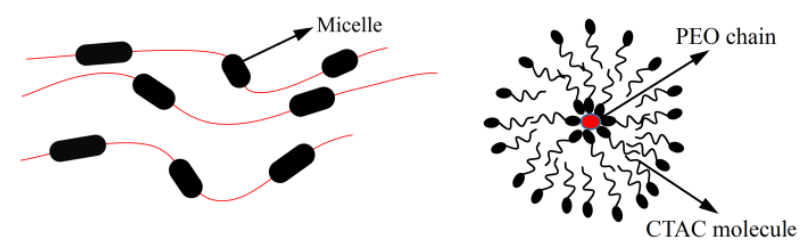

$\begin{array}{lll}\text { (a) Part of the new conformation of PEO }+\mathrm{CTAC} / \mathrm{NaSal} & \text { (b) Cross section of the new conformation }\end{array}$

Fig. 9 The sketch of the new conformation by the aggregation of PEO and $\mathrm{CTAC} / \mathrm{NaSal}$

Through investigating the drag reduction of the mixed solution of PEO and CTAC/NaSal in a two-dimensional channel (Pang et al., 2018), the present team proposed the aggregate model, namely, the formation of surfactant micelles along polymer chains (for short, MIP). The definite explanation is presented below. The molecular chains of PEO dissolved in water will dilate. The hydrophobic and hydrophilic groups are inside and outside the MIP, respectively. The hydrophilic head groups of CTAC take over water molecules connected to the PEO ether bonds, and thus a novel hydrogen bonds appear as a result of the strong polar interaction. The ringed conformation is formed due to the fact that the hydrophilic 
head groups of CTAC connect to ether bonds of PEO. And the hydrophobic tail groups connect to each other, which forms the outer ring again. Thus, the double molecules layer of CTAC around the PEO chain forms as the novel conformation, as schematically displayed in Fig. 9. The addition of NaSal can increase the amount of CTAC molecules bound to per PEO chain. Additionally, NaSal can stabilize the combination of CTAC micelles with the PEO chain so that the single chain complexes may be predominantly formed. It can be discovered from the present experimental results that the $D R$ pattern of the mixed solution is more similar to the PEO solution than the CTAC/NaSal one. Thus, it can be concluded that the polymer seems to dominate the dragreducing trend of the mixed solution, and the surfactant plays a role in enhancing the drag-reducing ability. The correctness of the aggregate model MIP is further proved. As can be seen from Fig. 9, the microstructure of MIP is somewhat similar to that of the micelles of surfactants, but their drag-reducing properties are not the same. With the addition of PEO, more MIP are formed, and the structure of MIP will become larger and denser. Therefore, the drag-reducing ability of the mixed solution is far better than that of the surfactant solution, and the synergistic effect of PEO and CTAC can greatly enhance the drag reduction.
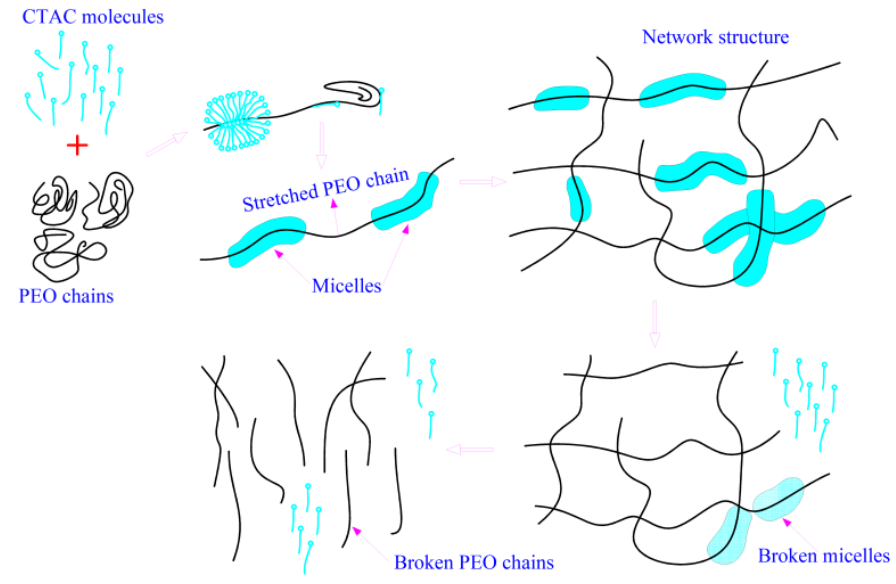

Fig.10 Evolution process of the new conformation by aggregation of $\mathrm{PEO}$ and $\mathrm{CTAC} / \mathrm{NaSal}$

According to the present experimental results, the net enhancement of the drag-reducing rate curve is further presented. The effect of temperature on the drag reduction of mixed solution is analyzed in detail. It is found that the drag-reducing effect is completely enhanced under the high temperature and the larger Reynolds number conditions. The drag reduction ability of PEO \& CTAC/NaSal solutions is much better than that of the only CTAC/NaSal or PEO solution. It means that the MIP combines the merit of the PEO chain and the CTAC/NaSal micelle. Namely, it has not only the better resistance ability to the high temperature and the strong shear but also can perform self-repair after being broken. When the MIP structure is destroyed under the adverse environment, the surfactant micelles attached to the PEO chains may first be destroyed. Correspondingly, the drag-reducing rate decreases to a certain extent. If the drag-reducing condition deteriorates further, the PEO chains will also be destroyed. Then, the drag-reducing rate will disappear completely as we have analyzed before (Pang et al., 2018). Fig. 10 shows the evolution process of the drag-reducing structures of PEO and $\mathrm{CTAC} / \mathrm{NaSal}$ as the drag-reducing environment tends to be bad.

Additionally, it can be seen from the present experiments that the drag-reducing rate is different for the same mixed solution at the different temperature. Thus it can be concluded that the MIP has the optimum structure. The formation of the optimum structure should be related to the microstructure of the PEO chain, which is greatly dependent on the temperature and the concentration. For the PEO solutions with the high drag-reducing rate (such as $75 \mathrm{ppm} \mathrm{CTAC} / \mathrm{NaSal}$ at $10^{\circ} \mathrm{C}$ ), the microstructure of the PEO chain seems difficult to form the optimal structure. Therefore, the drag-reducing enhancement is slight. When the temperature is higher than $20^{\circ} \mathrm{C}$, the PEO chain is fully stretched. At this time, the optimal structure seems to form easily. Correspondingly, the drag-reducing enhancement is notable. The change of the drag-reducing rate is much sharper with changing the $\mathrm{CTAC} / \mathrm{NaSal}$ concentration for the fixed the PEO concentration than with changing the PEO concentration for the fixed the CTAC/NaSal concentration. Thus it can be further concluded that the polymer chain should be the cornerstone of the MIP, and the amount of the surfactant molecules only influences the quality of the MIP structure. If the concentration ratio of PEO and CTAC/NaSal is very right, the properties of novel conformation may be better. The enhancement of drag reduction will be shaper, and thus the dosage of the drag-reducing additive can be reduced. Note that the concentration ratio of PEO and CTAC/NaSal, which is able to form the optimum structure of the MIP, should be deeply investigated in the following investigations.

\section{CONCLUSIONS}

In this paper, it is investigated on the $D R$ of the mixed aqueous solution of PEO \& CTAC/NaSal in a rotating disk apparatus. The influence of concentration, temperature and $R e$ on the $D R \%$ is investigated in detail. Some definite conclusions are summarized as below.

- It is discovered that the drag-reducing trend of the mixed solution is similar to that of the PEO solution. The influence of the CTAC/NaSal (or PEO) concentration on the $D R \%$ of the mixed solution is slighter at the low $R e$ than that at the large $R e$. For the CTAC/NaSal solution, the temperature and $R e$ ranges of $D R$ is greatly increased due to the addition of PEO.

- Comparing with the PEO or CTAC/NaSal solution, the mixed solution shows the good ability of drag reduction at the high temperature and/or the large $R e$. For all mixed solutions, the optimum temperature of $D R$ is about $30^{\circ} \mathrm{C}$.

- $\quad$ By analyzing the net difference of the drag-reducing rate (net $D D R \%$ ) between the mixed solution and the sum corresponding pure $\mathrm{PEO}$ and pure $\mathrm{CTAC} / \mathrm{NaSal}$ solution, it can be seen that the net enhancement of $D R$ is sharp only when the temperature is higher than $30^{\circ} \mathrm{C}$. For all mixed solutions, the difference of the $D R \%$ is the biggest at the temperature of $40^{\circ} \mathrm{C}$. Namely, the drag-reducing enhancement is the sharpest at the temperature of $40^{\circ} \mathrm{C}$.

\section{ACKNOWLEDGEMENTS}

We gratefully acknowledge the financial support from the NSFC Fund (No. 51376026 and 21908152).

\section{REFERENCES}

Al-Yaari, M., Al-Sarkhi, A., Hussein, I. A., and Abu Sharkh, B., 2013, "Effect of drag reducing polymers on surfactant- stabilized water-oil emulsions flow," Experimental Thermal and Fluid Science, 51, 319-331. https://doi.org/10.1016/j.expthermflusci.2013.08.015

Andrade, R. M., Pereira, A. S., and Soares, E. J., 2016, "Drag Reduction in Synthetic Seawater by Flexible and Rigid Polymer Addition Into a Rotating Cylindrical Double Gap Device," Journal of Fluids Engineering, 138(2), 1-10.

https://doi.org/10.1115/1.4031229

Cai, S. P., Suzuki, H., and Komoda, Y., 2012, "Drag-reduction of a nonionic surfactant aqueous solution and its rheological characteristics," Science China (Technological Sciences), 55(3), 772-778.

https://doi.org/10.1007/s11431-011-4728-y 
Chai, Y., Li, X., Geng, J., Pan, J., Huang, Y., and Jing, D., 2019, "Mechanistic study of drag reduction in turbulent pipeline flow over anionic polymer and surfactant mixtures," Colloid and Polymer Science, 297(7-8), 1025-1035.

https://doi.org/10.1007/s00396-019-04525-2

Chen, P., Yao, L., Liu, Y., Luo, J., Zhou, G., and Jiang, B., 2012, "Experimental and Theoretical Study of Dilute Polyacrylamide Solutions: Effect of Salt Concentration," Journal of Molecular Modeling, 18(7), 3153-3160

https://doi.org/10.1007/s00894-011-1332-9

Dai, X. D., Li, B., Li, L., Yin, S. M., and Wang, T., 2021, “Experimental research on the characteristics of drag reduction and mechanical degradation of polyethylene oxide solution," Energy Sources, Part A: Recovery, Utilization, and Environmental Effects, 43(8), 944-952. https://doi.org/10.1080/15567036.2019.1632988

Dai, X. D., Li, L., Yin, S., Zhang G. C., and Ge J. J., 2018, “The drag reduction and degradation characteristics of poly $\alpha$ olefin in diesel via rotating disk apparatus," Petroleum Science and Technology, 36(13), 981-986.

https://doi.org/10.1080/10916466.2018.1458118

DaRocha, C. M., Patruyo, L. G., Ramírez, N. E., Müller, A. J., and Sáez, A. E., 1999, "Porous media flow of poly (ethylene oxide)/ sodium dodecyl sulfate mixtures," Polymer Bulletin, 42(1), 109-116. https://doi.org/10.1007/s002890050441

Fakhruddin, S. K., Abdulbari, H. A., Sulaiman, A. Z., and Rafeeq H. A., 2018, "Investigating the improvement of degradation resistant with the addition of SDBS anionic surfactant to PEO polymer," MATEC Web of Conferences, 225, 06019.

https://doi.org/10.1051/matecconf/201822506019

Fu, Z. G., Iwaki, Y., Motozawa, M., Tsukahara, T., and Kawaguchi, Y., 2015, "Characteristic turbulent structure of a modified drag-reduced surfactant solution flow via dosing water from channel wall," International Journal of Heat and Fluid Flow, 53, 135-145. https://doi.org/10.1016/j.ijheatfluidflow.2015.03.006

Gu, Y. Q., Yu, S. W., Mou, J. G., Wu, D. H., and Zheng, S. H., 2020, "Research progress on the collaborative drag reduction effect of polymers and surfactants," Materials, 13(2), 444.

https://doi.org/10.3390/ma13020444

Hadri, F., Besq, A., Guillou, S., and Makhloufi, R., 2011, "Temperature and concentration influence on drag reduction of very low concentrated CTAC/NaSal aqueous solution in turbulent pipe flow," Journal of NonNewtonian Fluid Mechanics, 166(5-6), 326-331. https://doi.org/10.1016/j.jnnfm.2010.12.009

Han, W. J., Dong, Y. Z., and Choi, H. J., 2017, “Applications of watersoluble polymers in turbulent drag reduction," Processes, 5(2) 24. https://doi.org/10.3390/pr5020024

Hong, C. H., Choi, H. J., and Kim, J. H., 2008, "Rotating disk apparatus for polymer-induced turbulent drag reduction," Journal of Mechanical Science and Technology, 22(10), 1908-1913.

https://doi.org/10.1007/s12206-008-0731-z

Hou, Z., Li, Z., and Wang, H., 1999, "Interaction between poly(ethylene oxide) and sodium dodecyl- sulfonate as studied by surface tension, conductivity, viscosity, electron spin resonance and nuclear magnetic resonance," Colloid and Polymer Science, 277(11), 1011-1018. https://doi.org/10.1007/s003960050484

Kim, J. T., Kim, C. A., Zhang, K., Jang C. H., and Choi H. J., 2011, "Effect of polymer-surfactant interaction on its turbulent drag reduction," Colloids and Surfaces. A: Physicochemical and Engineering Aspects, 391(1-3), 125-129. https://doi.org/10.1016/j.colsurfa.2011.04.018

Kim, N. J., Kim, S., Lim, S. H., Chen, K., and Chun, W. G., 2010, "Measurement of drag reduction in polymer added turbulent flow," International Communications in Heat and Mass Transfer, 36(10), 10141019.

https://doi.org/10.1016/j.icheatmasstransfer.2009.08.002

Kong, M., Kang, B. X., and Luo, Y., 2016, "Study of the dissolution of Polyethylene oxide with a high molecular weight in water," China Pulp \& Paper, 35(12), 20-24.

https://doi.org/10.11980 / j.issn.0254-508X.2016.12.005

Lawrence, E. O., and Panagiota, A., 2019, "Separated oil-water flows with drag reducing polymer," Experimental Thermal and Fluid Science, 102, 467-478.

https://doi.org/10.1016/j.expthermflusci.2018.12.011

Lee, K. H., Zhang, K., and Choi, H. J., 2010, "Time dependence of turbulent drag reduction efficiency of polyisobutylene in kerosene," Journal of Industrial and Engineering Chemistry, 16(4), 499-520. https://doi.org/10.1016/j.jiec.2010.03.027

Lian, W. L., Sun, Z. J., Han, T. Y., and Xuan, Y. M., 2020, "Experiment study on the boiling heat transfer of liquid film in a rotating pipe," Frontiers in Heat and Mass Transfer, 14, 10.

https://doi.org/10.5098/hmt.14.10

Li, F. C., Kawaguchi, Y., and Hishida, K., 2004, "Investigation on the characteristics of turbulence transport for momentum and heat in a dragreducing surfactant solution flow," Physics of Fluids, 16(9), 3281-3295. https://doi.org/10.1063/1.1769375

Li, F. C., Kawaguchi, Y., and Segawa, T., 2005, "Reynolds-number dependence of turbulence structures in a drag-reducing surfactant solution channel flow investigated by particle image velocimetry," Physics of Fluids, 17(7), 104-116.

https://doi.org/10.1063/1.1941366

Liu, D. J., Wang, Q. H., and Wei, J. J., 2018, "Experimental study on drag reduction performance of mixed polymer and surfactant solutions," Chemical Engineering Research and Design, 132, 460-469.

Li, X., 2019, "Turbulent drag reduction by polymer additives: Fundamentals and recent advances," Physics of Fluids, 31(12), 121302. https://doi.org/10.1016/j.cherd.2018.01.047

Matras, Z., and Kopiczak, B., 2015, "Intensification of drag reduction effect by simultaneous addition of surfactant and high molecular polymer into the solvent," Chemical Engineering Research and Design, 96, 3542.

https://doi.org/10.1016/j.cherd.2015.02.006

Matras, Z., and Kopiczak, B., 2016, "The effect of surfactant and high molecular weight polymer addition on pressure drop reduction in pipe flow," Brazilian Journal of Chemical Engineering, 33(4), 933-943. https://doi.org/10.1590/0104-6632.20160334s20150440

Matras, Z., Malcher, T., and Gzyl-Malcher, B., 2008, "The influence of polymer-surfactant aggregates on drag reduction," Thin Solid Films, 516(24), 8848-8851.

https://doi.org/10.1016/j.tsf.2007.11.057

Mohamad, A. M., Musaab, K. R., Hayder, A. A., and Mohd H. S. I., 2016, "A novel polymer-surfactant complex mixture to improve diesel fuel flow in a rotating disk apparatus," Advances and Applications in Fluid Mechanics, 8, 669-685.

https://doi.org/10.17654/FM019030669

Mohsenipor, A. A., and Pal, R., 2013a, "Drag Reduction in Turbulent Pipeline Flow of Mixed Nonionic Polymer and Cationic Surfactant Systems," Canadian Journal of Chemical Engineering, 91(1), 190-201. 


\section{https://doi.org/10.1002/cjce.21618}

Mohsenipor, A. A., and Pal, R., 2013b, "Synergistic Effects of Anionic Surfactant and Nonionic Polymer Additives on Drag Reduction," Chemical Engineering Communications, 200(7), 935-958. https://doi.org/10.1080/00986445.2012.731661

Mohsenipor, A. A., and Pal, R., 2013c, "The Role of Surfactants in Mechanical Degradation of Drag-Reducing Polymers," Industrial \& Engineering Chemistry Research, 52(3), 1291-1302.

https://doi.org/10.1021/ie3024214

Mohsenipor, A. A., Pal, R., and Prajapati, K., 2013, "Effect of Cationic Surfactant Addition on the Drag Reduction Behaviour of Anionic Polymer Solutions," Canadian Journal of Chemical Engineering, 91(1), 181-189.

https://doi.org/10.1002/cjce.20686

Musaab, K. R., Mohamad, A. M., Hayder, A. A., and Mohd H. S. I., 2016a, "Enhancing the drag reduction phenomenon within a rotating disk apparatus using polymer-surfactant additives," Applied Sciences-Basel, 6(12), 334-355.

https://doi.org/10.3390/app6120355

Musaab, K. R., Mohamad, A. M., Hayder, A. A., and Mohd H. S. I., 2016b, "Investigating the effects of Surfactants on drag reduction performance of diesel fuel in a rotating disk apparatus," Journal of Purity, Utility Reaction and Environment, 5(1), 18-30.

Nagarajua, G., Garvandha, M., Murthy, J. V. R., 2019, "Mhd flow in a circular horizontal pipe under heat source/sink with sucting/injection on wall," Frontiers in Heat and Mass Transfer, 13, 6.

https://doi.org/10.5098/hmt.13.6

Nsom, B., and Latrache, N., 2018, "Measurement of Drag Reduction in Dilute Polymer Solution Using Triboelectric Effect," Applied Rheology, 28(2), 25922.

https://doi.org/10.3933/APPLRHEOL-28-25922

Pang, M. J., Xie, C. C., Zhang, Z., and Dai, J. R., 2018, "Experimental studies on drag reduction by coupled addition of nonionic polymer poly(ethylene oxide) and cationic surfactant cetyltrimethyl- ammonium chloride," Asia-Pacific Journal of Chemical Engineering, 13(4), e2218. https://doi.org/10.1002/apj.2218

Sandoval, G. B., and Soares, E. J., 2016, "Effect of combined polymers on the loss of efficiency caused by mechanical degradation in drag reducing flows through straight tubes," Rheologica Acta, 55(7), 559-569. https://doi.org/10.1007/s00397-016-0927-6

Soares, E. J., Sandoval, G. B., Silveira, L., Pereira, A. S., Trevelin, R., and Thomaz, F., 2015, "Loss of efficiency of polymeric drag reducers induced by high Reynolds number ows in tubes with imposed pressure," Physics of Fluids, 27(12), 125105.

https://doi.org/10.1063/1.4937594

Suksamranchit, S., Sirivat, A., and Jamieson, A. M., 2006, "Polymersurfactant complex formation and its effect on turbulent wall shear stress," Journal of Colloid and Interface Science, 294(1), 212-221.

https://doi.org/10.1016/j.jcis.2005.07.001

Suksamranchit, S., and Sirivat, A., 2007, "Influence of ionic strength on complex formation between poly(ethylene oxide) and cationic surfactant and turbulent wall shear stress in aqueous solution," Chemical Engineering Journal, 128(1), 11-20. https://doi.org/10.1016/j.cej.2006.10.003

Toms, B. A., 1948, "Some observations on the flow of linear polymer solutions through straight tubes at large Reynolds numbers," First International Congress on Rheology, Netherland.

Tsukahara, T., Hara, S., Kawada, S., and Kawaguchi, Y., 2016, "Experimental study on functionality of surfactant solution in turbulent heat transfer by varying local shear rate," International Journal of Heat and Mass Transfer, 102, 360-368.

https://doi.org/10.1016/j.ijheatmasstransfer.2016.06.024

Wang, Y., Yu, B., Zakin, J. L., and Shi, H. F., 2011, "Review on drag reduction and its heat transfer by additives," Advances in Mechanical Engineering, 3, 478749.

https://doi.org/10.1155/2011/478749

Wei, J. J., Kawaguchi, Y., Yu, B., and Feng, Z. P., 2006, "Rheological characteristics and turbulent friction drag and heat transfer reductions of a very dilute cationic surfactant solution," Journal of Heat Transfer, 128(10), 977-983.

https://doi.org/10.1115/1.2345422

Wei, J. J., Liu, F., and Liu, D. J., 2019, "Process in molecular dynamics simulations of surfactant solution for turbulent drag reduction," Chinese Journal of Theoretical and Applied Mechanics, 51(4), 971-990. https://doi.org/10.6052/0459-1879-18-372

Wei, J. J., Wang, J. F., Zhang, C. W., and Kawaguchi, Y., 2012, "Combined effects of temperature and Reynolds number on dragreducing characteristics of a surfactant solution," Advances in Mechanical Engineering, 90(5), 1304-1310.

https://doi.org/10.1002/cjce. 20622

White, C. M., and Mungal, M. G., 2008, "Mechanics and prediction of turbulent drag reduction with polymer additives," Annual Review of Fluid Mechanics, 40(1), 235-256. https://doi.org/10.1146/annurev.fluid.40.111406.102156

Wu, G., Ying, Z., and Jacques, L. Z., 2008, "Surfactant turbulent drag reduction in an enclosed rotating disk apparatus," Experiments in Fluids, 42(3), 459-469.

https://doi.org/10.1007/s00348-007-0253-y

Xu, N., Wei, J. J., and Kawaguchi, Y., 2016, "Rheology test on shear viscosity of surfactant solution: characteristic time, hysteresis phenomenon and fitting equation," Industrial and Engineering Chemistry Research, 55(20), 5817-5824.

https://doi.org/10.1021/acs.iecr.6b00703

Yu, B., and Kawaguchi, Y., 2006, "Parametric study of surfactantinduced drag-reduction by DNS," International Journal of Heat and Fluid Flow, 27(5), 887-894.

https://doi.org/10.1016/j.ijheatfluidflow.2006.03.013

Zhang, K., Choi, H. J., and Jang, C. H., 2011, “Turbulent drag reduction characteristics of poly(acrylamide-co- acrylic acid) in a rotating disk apparatus," Colloid and Polymer Science, 289(17-18), 1821-1827. https://doi.org/10.1007/s00396-011-2502-0

Zhang, X., Duan, X. L., and Muzychka, Y., 2018, "New mechanism and correlation for degradation of drag-reducing agents in turbulent flow with measured data from a double-gap rheometer," Colloid and Polymer Science, 296(4), 829-834.

https://doi.org/10.1007/s00396-018-4300-4 